A. Ceriello $\cdot$ M. Hanefeld $\cdot$ L. Leiter $\cdot$ L. Monnier •

D. Owens $\cdot$ N. Tajima $\cdot$ J. Tuomilehto $\cdot$

The International Prandial Glucose Regulation Study Group

\title{
To: Strey CH, Young J, Collier M, Florkowski CM, Shand BI, Scott RS (2004) The postprandial state does not impair endothelial function in women with Type 2 diabetes irrespective of glycaemic control. Diabetologia 47:1838-1846
}

Received: 17 December 2004 / Accepted: 7 March 2005 / Published online: 10 June 2005

(C) Springer-Verlag 2005

To the Editor: In a recent article, Strey and co-workers reported that the postprandial state has no negative effect on endothelial function in postmenopausal women with type 2 diabetes [1]. However, the same authors also stated that their results were not consistent with many other

\author{
A. Ceriello $(\bowtie)$ \\ Department of Pathology and Medicine, Experimental and \\ Clinical, University of Udine, \\ P.le S. Maria della Misericordia, 1, \\ 33100 Udine, Italy \\ e-mail: ceriello@uniud.it \\ Tel.: +39-0432-559813 \\ Fax: +39-0432-42097
}

\section{Hanefeld}

Centre for Clinical Studies, Technical University of Dresden, Dresden, Germany

\section{Leiter}

Division of Endocrinology and Metabolism,

St Michael's Hospital, University of Toronto,

Toronto, Canada

L. Monnier

Department of Metabolism, Lapeyronie Hospital,

Montpellier, France

D. Owens

Diabetes Research Unit, Academic Centre,

Llandough Hospital,

Penarth, Wales, UK

\section{N. Tajima}

Division of Diabetes and Endocrinology,

Department of Internal Medicine,

Jikei University School of Medicine,

Tokyo, Japan

\section{J. Tuomilehto}

Diabetes and Genetic Epidemiology Unit,

National Public Health Institute,

Helsinki, Finland reports [1]. We, the International Prandial Glucose Regulation (PGR) Study Group, have several concerns with the results of the study.

Firstly, no information was available on the concomitant therapy undertaken by the diabetic women; however, the mean blood pressure was significantly increased in the diabetic group, particularly pre-intervention ( $104.5 \pm 4.0 \mathrm{vs.}$ $91.2 \pm 3.2 \mathrm{mmHg}, p<0.05$, diabetic and non-diabetic respectively), and was consistently high in the post-intervention period $(100.3 \pm 3.8 \mathrm{mmHg})$. This suggests that some, or many, of these patients were hypertensive and, presumably, undergoing treatment. As it is well known that many compounds used in the treatment of hypertension, e.g. calcium channel blockers, ACE inhibitors and angiotensin 1 blockers, have a protective effect against endothelial dysfunction, one could hypothesise that the deleterious effect of the postprandial state may simply have been counter-balanced by the hypertensive therapy [2]. Secondly, patients showed the same levels of LDL as the control group, as well as reduced levels of HDL, but, surprisingly, HDL increased following intervention. This suggests that a statin may have been used during the study, which has been shown to protect the endothelium in postprandial conditions [3]. Thirdly, eight patients $(42 \%)$ were taking sulphonylurea. This is another interesting point, as gliclazide has been shown to have a protective effect on the endothelium [4].

Finally, the most important reason why the intensive glucose control had no effect on postprandial endothelial dysfunction is that the investigators were unable to control effectively the postprandial glucose excursions. In this respect, their failure supports our hypothesis that perfect control of postprandial hyperglycaemia is essential in protecting the endothelium. The postprandial glucose value in the diabetic group was still $12.89 \mathrm{mmol} / \mathrm{l}$, and the highsensitivity C-reactive protein level was $6.85 \mathrm{mg} / \mathrm{l}$ (preintervention level $5.82 \mathrm{mg} / \mathrm{l}$ ). Glycaemic control was, 
therefore, far from optimal. It has been shown that only near-normal glucose control leads to a normalisation of impaired endothelial function in the postprandial state [5].

We, the International PGR Study Group, believe that studies of this sort need careful evaluation, as they may create confusion about the role of prandial glucose regulation and its benefits in lowering the risk of cardiovascular disease and achieving optimal glycaemic control. It has been reported that cardiovascular mortality increases steadily with increasing post-challenge glucose [6]. Prandial glucose regulation is of great relevance to clinical practice and is included in many guidelines all over the world [7].

\section{References}

1. Strey CH, Young J, Collier M, Florkowski CM, Shand BI, Scott RS (2004) The postprandial state does not impair endothelial function in women with Type 2 diabetes irrespective of glycaemic control. Diabetologia 47:1838-1846
2. Ceriello A (2003) New insights on oxidative stress and diabetic complications may lead to a 'causal' antioxidant therapy. Diabetes Care 26:1589-1596

3. Ceriello A, Taboga C, Tonutti L et al (2002) Evidence for an independent and cumulative effect of postprandial hypertriglyceridemia and hyperglycaemia on endothelial dysfunction and oxidative stress generation: effects of short- and long-term simvastatin treatment. Circulation 106:1211-1218

4. Fava D, Cassone-Faldetta M, Laurenti O, De Luca O, Ghiselli A, De Mattia G (2002) Gliclazide improves anti-oxidant status and nitric oxide-mediated vasodilation in Type 2 diabetes. Diabet Med 19:752-757

5. Ceriello A, Cavarape A, Martinelli L et al (2004) The postprandial state in type 2 diabetes and endothelial dysfunction: effects of insulin aspart. Diabet Med 21:171-175

6. The DECODE Study Group (2003) Is the current definition for diabetes relevant to mortality risk from all causes and cardiovascular and noncardiovascular diseases. Diabetes Care 26: 688-696

7. Ceriello A, Hanefeld M, Leiter L et al (2004) Postprandial glucose regulation and diabetic complications. Arch Intern Med 164:2090-2095 